\title{
Isolated tricuspid stenosis
}

\author{
P. Finnegan and L. D. Abrams \\ From Queen Elizabeth Hospital, Birmingham
}

A case of isolated tricuspid stenosis of rheumatic aetiology treated by commisurotomy is described. Haemodynamic studies performed to years after operation show a trivial tricuspid valve pressure gradient and a normal cardiac output at rest and on exercise.

Isolated tricuspid stenosis is rare but it may be rheumatic (Durosiez, 1868; Gordon et al., 1957; Killip and Lukas, 1958), congenital (Lewis, 1945), due to disseminated lupus erythematosus (Gibson and Wood, I955), or of unknown aetiology (Krook, Biorck, and Wulff, I955; Sapirstein and Baker, 1963). Most commonly tricuspid stenosis is a sequel to rheumatic fever and then it is almost invariably associated with lesions of the other valves, particularly mitral stenosis. Haemodynamic evaluation of the long-term results of surgical treatment of isolated tricuspid stenosis has not been reported previously.

\section{Case report}

A 21-year-old man had acute rheumatic fever when he was 7 years old. The illness was treated by three months' bed-rest and he made a good recovery. At the age of 20 he complained of fatigue and breathlessness which gradually increased in severity until his admission to hospital for investigation in August 1962. There was no history of orthopnoea, paroxysmal nocturnal dyspnoea, or ankle swelling.

Examination showed that the jugular venous pressure was raised and there were prominent ' $a$ ' waves in the jugular venous pulse. The apex beat was in the fifth intercostal space at the midclavicular line. In the tricuspid area there was a loud first heart sound, middiastolic, and presystolic murmurs. These findings were confirmed by phonocardiography and jugular phlebography (Fig. I). The liver was not enlarged and there was no ankle oedema. The electrocardiogram showed $P$ waves greater than $3 \mathrm{~mm}$ in height in leads VI and V2.

Radiographically the overall cardiac size was within normal limits and in particular there was no right or left atrial enlargement (Fig. 2a). The results of cardiac catheterization are shown in the Table; there was no evidence of an intracardiac shunt and the response of the cardiac output to exercise was moderately impaired.

\section{Operation}

The heart was exposed through a left anterior fourth space thoracotomy with transection of the sternum. The right atrium was large, but the other chambers were of normal size.

The tricuspid valve was explored through the right atrium. The orifice of the tricuspid valve was circular, $1.5 \mathrm{~cm}$ in diameter, and placed eccentrically close to the valve ring on the right. There was very slight regurgitation, the valve tissue itself was thin, and the valve was very mobile. A Tubbs' dilator was introduced through the tip of the right ventricle and the valve was split so that it opened to $4 \times 3 \mathrm{~cm}$, the split being in the commissure between the anterior and septal cusps. There was no increase in regurgitation.

The mitral valve was explored through the left atrium. The valve ring was small, being $3.75 \mathrm{~cm}$ in diameter, and there was slight thickening of the valve but no reduction in opening or mobility of the valve.

The patient's postoperative course was uneventful and he has since remained free of symptoms.

Examination in 1972 showed that the pulse was regular and the jugular venous pressure was not increased. The apex beat was in the fifth intercostal space just outside the midclavicular line, the first heart sound was loud at the apex and in the tricuspid area, but there was no opening snap and there were no murmurs. The only other noteworthy clinical findings were the presence of an arcus senilis and the biochemical features of a type II hyperlipoproteinaemia.

The slight increase in cardiac size clinically was confirmed radiographically (Fig. 2b) but the left atrium remained normal in size. The electrocardiogram showed that the $P$ waves in VI and V2 were less than $2 \mathrm{~mm}$ in height and the only abnormality was slight ST segment depression in V5 to V6. The results of cardiac 


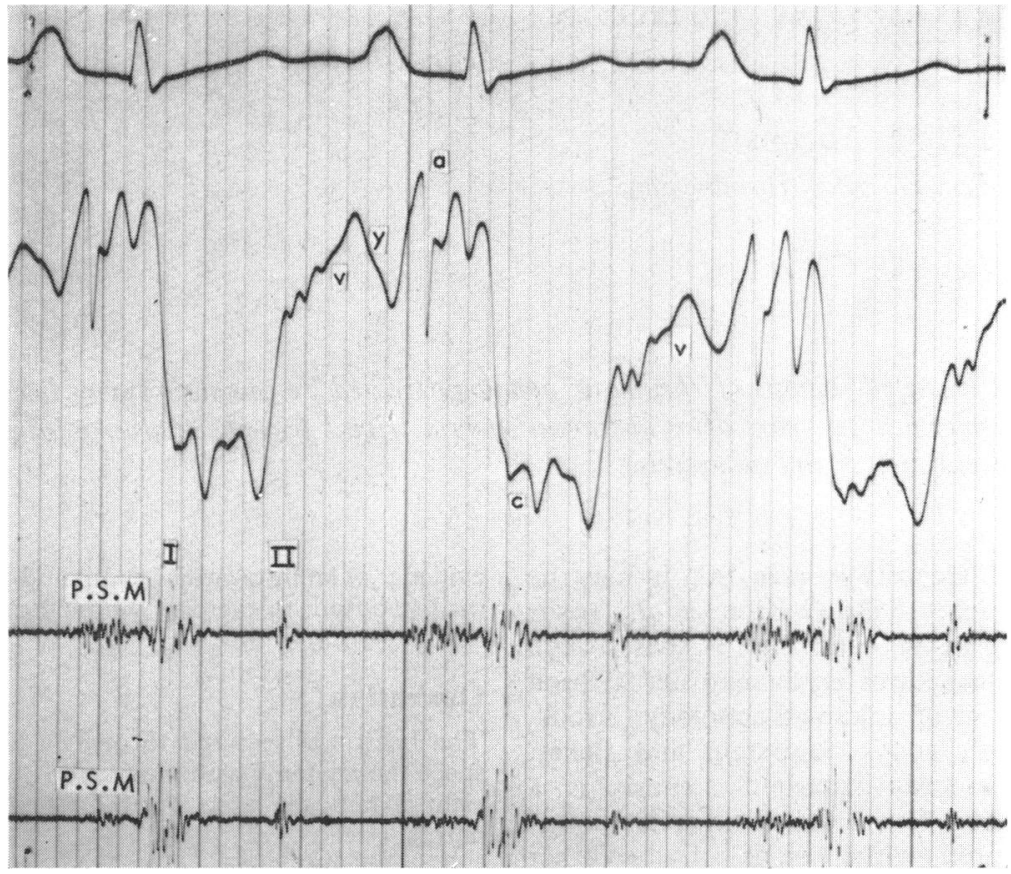

F I G. I Fugular phlebogram showing tall ' $a$ ' waves and slow ' $y$ ' descent. The presystolic murmur is best seen in the tracing recorded at the left sternal edge. The traces are, from the top, standard lead II of the electrocardiogram, the jugular phlebogram, phonocardiograms at the left sternal edge and at the apex.

TABLE Cardiac catherization data

\begin{tabular}{|c|c|c|c|c|}
\hline & \multicolumn{2}{|l|}{1962} & \multicolumn{2}{|l|}{1972} \\
\hline & $\overline{\text { Rest }}$ & $\overline{\text { Exercise }}$ & Rest & Exercise \\
\hline \multirow[t]{2}{*}{ Right atrial pressure (mmHg) } & $a=20$ & $a=28$ & $a=2$ & $a=5$ \\
\hline & $v=10$ & $v=15$ & $\mathrm{~V}=-\mathrm{I}$ & $\mathbf{v}=\mathbf{2}$ \\
\hline Right ventricular pressure (mmHg) & $25 / 5$ & $4 \mathrm{I} / \mathrm{10}$ & $23 / 1$ & $39 / 3$ \\
\hline Tricuspid presystolic gradient (mmHg) & 15 & 18 & $\mathbf{I}$ & 2 \\
\hline Mean pulmonary artery pressure $(\mathrm{mmHg})$ & 17 & 30 & 13 & 28 \\
\hline Mean pulmonary wedge pressure (mmHg) & 12 & 14 & 6 & 16 \\
\hline Cardiac index $\left(1 . / \mathrm{min}\right.$ per $\left.\mathrm{m}^{2}\right)$ & $3 \cdot 2$ & $5 \cdot 2$ & $3 \cdot 0$ & $6 \cdot 3$ \\
\hline $\mathrm{O}_{2}$ index $\left(\mathrm{ml} / \mathrm{min}\right.$ per $\left.\mathrm{m}^{2}\right)$ & 186 & $75 \mathrm{I}$ & 131 & 637 \\
\hline PVR (dyn sec $\mathrm{cm}^{-5}$ ) & 68 & 133 & IOI & 81 \\
\hline
\end{tabular}



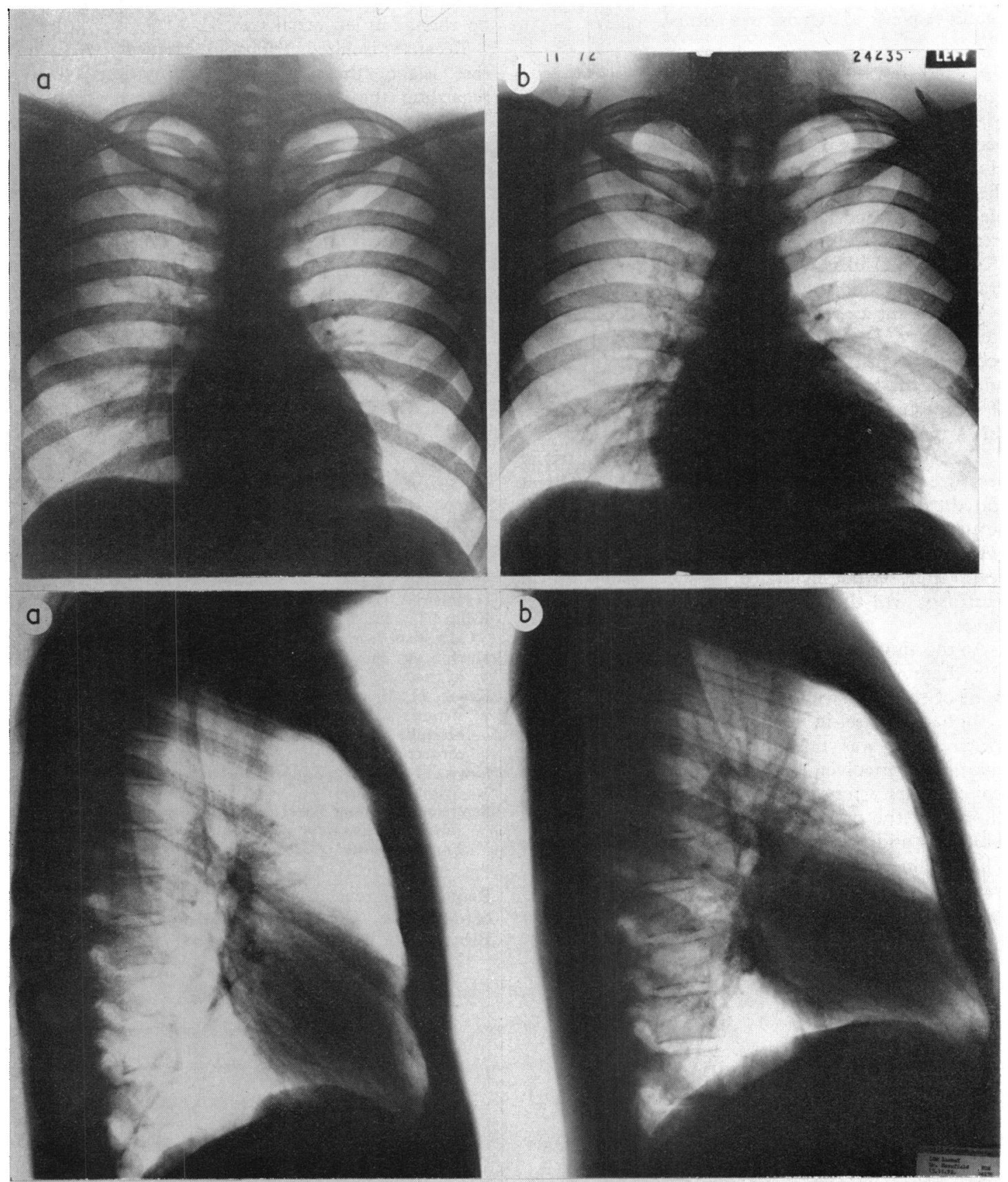

FIG. 2 a) Chest $x$-rays in 1962; the overall cardiac size is within normal limits, there is no right or left atrial enlargement; $b$ ) chest $x$-rays in 1972; a significant increase in cardiac size, no change in size of the right or left atrium. 
catheterization are shown in the Table. The cardiac output response to exercise was normal.

\section{Discussion}

Postoperative haemodynamic studies in patients with tricuspid stenosis and mitral stenosis have been reported by Kitchin and Turner (1964) and Hollman (1956). In both reports the gradient across the tricuspid valve was reduced but not completely abolished. In a case of isolated tricuspid stenosis recatheterized 14 months after operation (Killip and Lukas, 1958) a significant tricuspid gradient persisted.

We present a case of tricuspid stenosis of moderate severity. Fatigue and breathlessness commonly occur in tricuspid stenosis and are usually attributed to the low cardiac output. In this case relief of symptoms occurred promptly after operation and this improvement has been maintained.

Ten years after operation there were trivial pressure gradients across the tricuspid valve at rest and during exercise. The response of the cardiac output to exercise (Donald et al., 1955) which had been impaired before operation was normal Io years later. Other evidence of successful surgical treatment was the regression of the tall peaked $P$ waves.

At the time of the original diagnosis and operation there was no evidence of rheumatic involvement of the other valves. In the intervening period a slight increase in heart size had occurred for which there was no obvious reason. Rheumatic myocardial involvement is a possible explanation and coronary artery disease must also be considered in view of the presence of a type II hyperlipoproteinaemia and the development of an arcus senilis. The rise in pulmonary wedge pressure on exercise was slightly greater than normal, and this may indicate a mild degree of left ventricular failure or alternatively mitral stenosis. On the other hand, the patient was quite asymptomatic and there had been no change in left atrial size.

Because isolated tricuspid stenosis is such a rare lesion, there is little information available regarding the prognosis after surgical treatment. This case report indicates that the long-term prognosis in terms of symptomatic relief and haemodynamic improvement may be excellent.

The authors wish to acknowledge with gratitude $\mathrm{Mr}$. $T$. Dee of the Department of Medical Illustration, Queen Elizabeth Hospital, and Nurse M. Booth, Miss J. Blackhall, Mrs. J. Taylor, and Mr. J. Milton for technical help.

\section{References}

Donald, K. W., Bishop, J. M., Cumming, G., and Wade, O. L. (1955). The effect of exercise on the cardiac output and circulatory dynamics of normal subjects. Clinical Science, $14,37$.

Durosiez, P. L. (1868). Du retrecissement de la tricuspide. Gazette des Hôpitaux, Paris, 41, 310.

Gibson, R., and Wood, P. (1955). The diagnosis of tricuspid stenosis. British Heart fournal, 17, 552.

Gordon, A. J., Genkins, G., Grishman, A., and Nabatoff, R. A. (1957). Tricuspid stenosis. American fournal of Medicine, 22, 306.

Hollman, A. (1956). Tricuspid valvotomy. Lancet, 1, 535.

Killip, T., and Lukas, D. S. (1958). Tricuspid stenosis. American fournal of Medicine, 24, 836.

Kitchin, A., and Turner, R. (1964). Diagnosis and treatment of tricuspid stenosis. British Heart fournal, 26, 354 .

Krook, H., Biorck, G., and Wulff, H. B. (1955). Tricuspid stenosis and constrictive pericarditis in one patient successfully treated by simultaneous valvulotomy and pericardectomy. American Heart fournal, 49, 467.

Lewis, T. (1945). Congenital tricuspid stenosis. Clinical Science, 5, 26r.

Sapirstein, W., and Baker, C. B. (1963). Isolated tricuspidvalve stenosis. Report of a surgically treated case. New England fournal of Medicine, 269, 236.

Requests for reprints to Dr. P. Finnegan, Department of Medicine, Queen Elizabeth Hospital, Edgbaston, Birmingham $\mathrm{Br} 52 \mathrm{TH}$. 